\title{
Orthodontic treatment needs in the western region of Saudi Arabia: a research report
} Ali H Hassan*

Address: P.O. Box 80209, Jeddah 21589, Preventive Dental Sciences Department, Faculty of Dentistry, King Abdulaziz University, Jeddah, Saudi Arabia

Email: Ali H Hassan* - aliresearch@gawab.com

* Corresponding author

Published: 18 January 2006

Head \& Face Medicine 2006, 2:2 doi:10.1 186/1746-160X-2-2

This article is available from: http://www.head-face-med.com/content/2/1/2

(c) 2006 Hassan; licensee BioMed Central Ltd.

This is an Open Access article distributed under the terms of the Creative Commons Attribution License (http://creativecommons.org/licenses/by/2.0), which permits unrestricted use, distribution, and reproduction in any medium, provided the original work is properly cited.
Received: II September 2005

Accepted: 18 January 2006

\begin{abstract}
Background: Evaluation of self perceived and actual need for orthodontic treatment helps in planning orthodontic services and estimating the required resources and man power. In the present study, the perceptive need as evaluated by patients and the actual need to orthodontic treatment, as assessed by orthodontists, were evaluated at two types of dental practices in the city of Jeddah using the Index of Orthodontic Treatment Need (IOTN).
\end{abstract}

Methods: A consecutive sample of 743 adults seeking orthodontic treatment at two different types of dental practices in Jeddah; King Abdulaziz University, Faculty of Dentistry (KAAU) (Free treatment) and two private dental polyclinics (PDP) (Paid treatment), was examined for orthodontic treatment need using the dental health component (DHC) of the IOTN. The selfperceived need for orthodontic treatment was also determined using the aesthetic component (AC) of the IOTN. The IOTN score and the incidence of each variable were calculated statistically. $\mathrm{AC}$ and $\mathrm{DHC}$ categories were compared using the Chi-Square and a correlation between them was assessed using Spearman's correlation test. AC and DHC were also compared between the two types of dental practices using the Chi-Square.

Results: The results revealed that among the 743 patients studied, $60.6 \%$ expressed no or slight need for treatment, $23.3 \%$ expressed moderate to borderline need and only $16.1 \%$ thought they needed orthodontic treatment. Comparing these estimates to professional judgments, only $15.2 \%$ conformed to little or no need for treatment, $13.2 \%$ were assessed as in borderline need and $71.6 \%$ were assessed as in need for treatment $(\mathrm{p}<0.00 \mathrm{I})$. Spearman's correlation test proved no correlation $(r=-.045)$ between the two components. Comparing the AC and the DHC between the KAAU group and PDP group showed significant differences between the two groups $(p<$ 0.001 ).

Conclusion: Patient's perception to orthodontic treatment does not always correlate with professional assessment. The IOTN is a valid screening tool that should be used in orthodontic clinics for better services especially, in health centers that provide free treatment. 


\section{Background}

Orthodontic treatment is an elective treatment that depends on the perception of both the patient and the treating orthodontist. In Saudi Arabia, governmental sectors provide free orthodontic treatment for Saudi citizens. This has generated long waiting lists of patients that can extend for two to four years. Evaluation of self perceived and actual need for orthodontic treatment as well as other factors affecting these needs such as personal, sociodemographic, and psychosocial factors help in planning orthodontic services and estimating the required resources and manpower. Moreover, unnecessary referrals by general practitioners and lengthy waiting lists for orthodontic treatment can be eliminated by limiting free treatment to patients with malocclusions sever enough to warrant treatment $[1,2]$. It may also predict patients' level of interest and motivation toward the orthodontic treatment, which could help in planning educational programs in schools and media to increase patient's awareness and to overcome obstacles and barriers in seeking treatment [3].

Perceptive or self assessed need to dental care is reported to be associated with certain signs and symptoms [4], socio-demographic factors and satisfaction with previous dental treatment $[5,6]$. Previous studies have shown differences between patients' and professionals' perception on orthodontic treatment need [8-13]. It seems that normative or actual need as assessed by dental professionals may not be linked to patients' perceptions unless the condition has progressed sufficiently to be symptomatic [7]. Several indices were developed to evaluate malocclusion, such as the IOTN [11], PAR (Peer Assessment Rating Index) [14] and ICON (Index of Complexity, outcome and Need) [15]. The IOTN and the ICON can serve as neutral instruments to determine treatment needs and to allocate financial resources for orthodontic cases [16]. Although the IOTN and the ICON are similar and largely in agreement in measuring treatment needs of patients from different ethnic backgrounds [17], the IOTN has been used extensively in literature to evaluate actual and perceptive treatment needs in different ethnic backgrounds and it seems to be a more popular research tool in the Middle East than the ICON [18-32]. In addition, the IOTN is simpler than the ICON in assessing treatment needs since ICON was designed to measure complexity of treatment in addition to treatment needs [15].

The IOTN is a scoring system for malocclusion, developed by Brook \& Shaw (1989) [11]. It consists of two independent components; the DHC, which is a five grade index that records the dental health need for orthodontic treatment, and the AC that records the aesthetic need for orthodontic treatment using a ten grade standardized ranking scale of colored photographs showing different levels of dental attractiveness. In Saudi Arabia, not a single study has been conducted regarding treatment needs among regular orthodontic patients.

The objectives of the present study were:

1 - To assess the perceptive and actual treatment needs for orthodontic treatment among subjects seeking orthodontic treatment in the city of Jeddah using the IOTN

2- To compare those subjects attending a governmental dental clinic (KAAU), with those attending PDP utilizing the IOTN.

\section{Methods}

A consecutive sample of 743 subjects (aged 17-24 years) seeking orthodontic treatment was used in this study. The sample was collected from two different types of practices; KAAU $(\mathrm{N}=489)$ and two PDPs in the city of Jeddah $(\mathrm{N}=$ 254) during the period of August-November 2004. All subjects were of Arabic descendants and with no history of

Table I: The incidence of the orthodontic problems as assessed by the DHC of the IOTN

\begin{tabular}{|c|c|c|c|c|c|c|}
\hline Orthodontic Problem & Incidence \% & Grade I & Grade 2 & Grade 3 & Grade 4 & Grade 5 \\
\hline Pre/post-normal occlusion & 3 & & 3 & & & \\
\hline Displacement & 89.1 & 3.6 & 25.5 & 16.4 & 43.6 & \\
\hline Crossbite & 44.5 & & 14.5 & 13.6 & 16.4 & \\
\hline Open bite & 20 & & 9.1 & 6.4 & 4.5 & \\
\hline Overbite & 33.6 & & 18.2 & 8.2 & 7.3 & \\
\hline Overjet & 33.6 & & 16.4 & 9.1 & 5.5 & 2.7 \\
\hline Reverse overjet & 3.6 & & & & 2.7 & 0.9 \\
\hline Scissors bite & 10.9 & & & & 10.9 & \\
\hline Partially erupted & 9.1 & & & & 9.1 & \\
\hline Impaction & 8.2 & & & & & 8.2 \\
\hline Submerged deciduous & 0 & & & & & 0 \\
\hline Supernumerary & .9 & & & & 0.9 & \\
\hline Hypodontia & 3.6 & & & & 3.6 & 0 \\
\hline Cleft lip-Palate & 3.9 & & & & & 3.9 \\
\hline
\end{tabular}


Table 2: Comparison of the AC and the DHC overall grades

\begin{tabular}{|c|c|c|c|c|c|c|}
\hline \multirow[t]{2}{*}{ Group/Grade } & \multicolumn{2}{|c|}{ AC } & \multicolumn{2}{|c|}{ DHC } & \multirow[t]{2}{*}{ Chi-Square } & \multirow[t]{2}{*}{ P-value } \\
\hline & $\%$ & $N$ & $\%$ & $N$ & & \\
\hline No/Slight Need & 60.6 & 450 & 15.2 & 113 & 201.007 & $0.000 *$ \\
\hline Moderate need & 23.3 & 173 & 13.2 & 98 & 20.756 & $0.000^{*}$ \\
\hline Need TX & 16.1 & 119 & 71.6 & 532 & 262.011 & $0.000^{*}$ \\
\hline Total & & 742 & & 743 & & \\
\hline
\end{tabular}

* Significant at $\mathrm{p}<0.00 \mathrm{I}$ at I d.f.

orthodontic treatment. The treatment at KAAU is free of charge while the treatment at PDPs is quite expensive for the general Saudi population. All subjects who were enrolled in the study signed a consent form. Each subject was examined for orthodontic treatment need using the DHC of the IOTN. Additionally, the self-perceived need for orthodontic treatment was determined by asking each subject to evaluate his or her own attractiveness by comparing it to the standard photographs of the $\mathrm{AC}$ of the IOTN. Two examiners were involved in the study, one for the DHC and the other for the AC. The examiners were trained to use the IOTN following the instructions provided with the IOTN materials. The IOTN score and the incidence of each variable were calculated statistically. The sample used in the present study was distribution free and therefore non-parametric tests were used. The AC and DHC categories were compared between the two groups using the Chi-Square. The DHC and the AC were also compared using the Chi-Square and were correlated using Spearman's Correlation coefficient. The protocol of the present study was approved by the Ethical Committee of the Faculty of Dentistry at King Abdulaziz University.

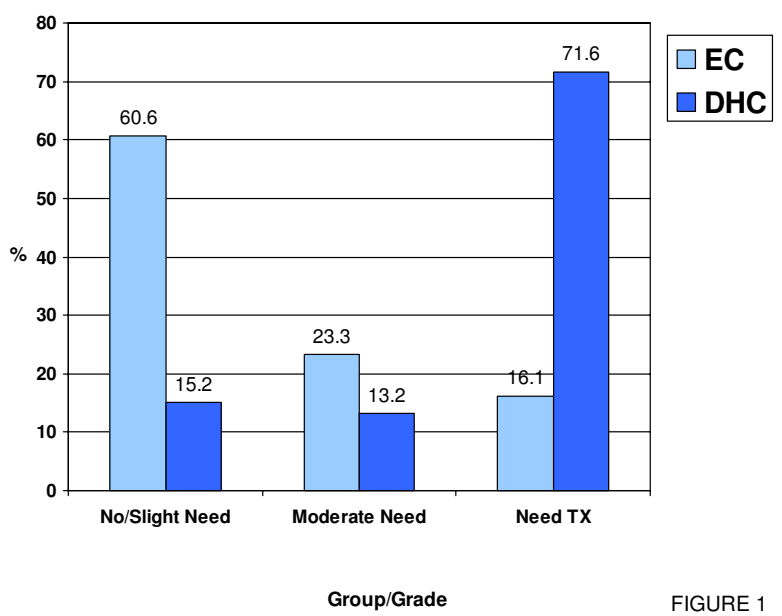

Figure I

Graphical representation table 2.

\section{Results}

The highest incidence of orthodontic problems in the current study was for displacement $(89.1 \%)$, followed by crossbite $(44.5 \%)$, deep overbite $(33.6 \%)$, increased overjet (33.6) and openbite (20\%). Impaction incidence was relatively low (8.2\%). The incidence of cleft lip and palate was $3.9 \%$ (Table 1 )

Results of the AC revealed that among the 743 patients studied, $60.6 \%$ expressed no or slight need for treatment, while $23.3 \%$ expressed moderate to borderline need and $16.1 \%$ expressed great need for orthodontic treatment. Comparing these estimates to professional judgments using the Chi Square, the DHC was significantly $(<0.001)$ different from the AC in the three groups; $15.2 \%$ had little to no treatment need (grades I \& II), $13.2 \%$ had borderline treatment need (grade III) and $71.6 \%$ had a great need for orthodontic treatment (grade IV \& V) (Table 2 \& Figure 1). Spearman's correlation between the AC and DHC proved no correlation $(\mathrm{r}=-0.045)$ between the two components.

Comparing the grades of DHC between the KAAU group and the PDP group (Table 3 \& Figure 2) revealed that the proportion of the sample estimated to have little to no treatment need (Grade I \& II) was significantly higher in the KAAU group (18.2\%) than that of PDP Group (9.4\%) $(\mathrm{p}<0.001)$. The border line proportion (Grade III) was insignificantly different between the two groups. The proportion of the sample estimated to have a great treatment need was significantly higher in the PDP group than the KAAU group $(\mathrm{p}<0.001)$.

Comparing the grades of the AC between the KAAU group and the PDP group (Table 4 \& Figure 3 ) revealed significant differences between the two groups; no or slight treatment need was higher in the KAAU group $(72.7 \%)$ than PDP group (37.4\%) and border line and great treatment needs were higher in the PDP group $(40.55 \%$ \& $22.04 \%$ respectively) than in the KAAU group $(14.3 \%$ \& $12.9 \%$ respectively). 
Table 3: Comparison of the proportions of the two samples estimated to need orthodontic treatment (DHC)

\begin{tabular}{|c|c|c|c|c|c|c|}
\hline \multirow[t]{2}{*}{ Group/Grade } & \multicolumn{2}{|c|}{ KAAU } & \multicolumn{2}{|c|}{ PDP } & \multirow[t]{2}{*}{ Chi-Square } & \multirow[t]{2}{*}{ P-value } \\
\hline & $\%$ & $N$ & $\%$ & $N$ & & \\
\hline Little/No TX. (Gr.I\&II) & 18.2 & 89 & 9.4 & 24 & 37.389 & $0.000 *$ \\
\hline Border line (Gr.III) & 11.8 & 58 & 15.7 & 40 & 3.306 & 0.069 \\
\hline Need TX. (Gr.IV\&V) & 70 & 342 & 74.9 & 190 & 34.429 & $0.000 *$ \\
\hline Total & & 489 & & 254 & & \\
\hline
\end{tabular}

* Significant at $\mathrm{p}<0.001$

\section{Discussion}

The results of the DHC shed some light on the pattern of malocclusion that is seen in the city of Jeddah, Saudi Arabia, which is dominant mainly of displacement, crossbite, deep bite and increased overjet. However, larger scale studies are required to evaluate the actual pattern of malocclusion in the western region of Saudi Arabia via conducting survey studies on a random sample. The age group targeted in the present study was different than most of the previous studies $[1,8,9,13,19]$, which were conducted on children and adolescents who are less reliable in their perception than adults, especially when using the IOTN which moderately reflects the subjective perception of dental aesthetics and demand for orthodontic treatment [30].

The significant differences between the AC and DHC and the negative weak correlation between the perceptive and actual need for orthodontic treatment indicates a general lack of awareness among the Saudis about the severity of their existing malocclusion. This can be attributed to their weak oral health knowledge as well as parents' neglect towards malocclusion. This is in agreement with several other studies [8-10]. Moreover, the perception of occlusal traits in the buccal segments is generally underestimated by people when compared to those present in the anterior segment $[22,23]$. The results can also be attributed to the nature of the IOTN itself. The scores of the DHC may have been exaggerated by the rank of displacement, which would give a high score in otherwise normal occlusion. In addition, the standard photographs of the AC do not show common orthodontic problems such as open bite, which represents a relatively high incidence in the studied sample (20\%). This may have misled those subjects with openbite in their perception of their malocclusion. Also, there is no evidence of how the severity of those traits is perceived by people. These shortcomings of the IOTN indicate the need to study the appropriateness of the IOTN or ICON as an index for the Saudi Arabians or even to develop a new index that suits such population.

The results have also shown less awareness and appreciation of the severity of malocclusion among patients seeking treatment in a governmental dental clinic such as KAAU, when compared to those paying for their treatment at private dental polyclinics. This could explain the
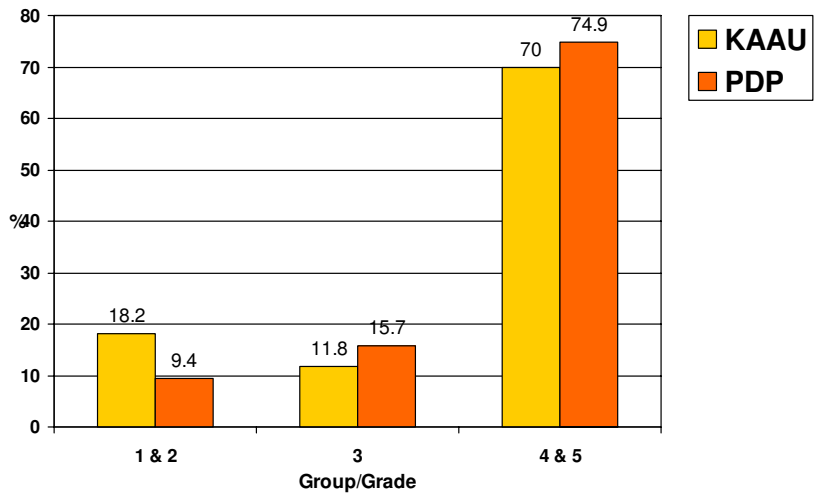

FIGURE 2

Figure 2

Graphical representation of table 3.

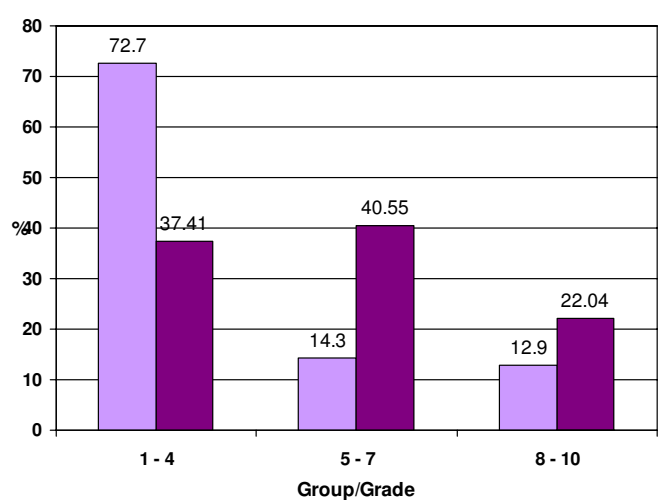

$\square$ KAAU

口PDP

FIGURE 3

Figure 3

Graphical representation of table 4 . 
Table 4: Comparison of the Perceptive Need to Orthodontic Treatment (AC) between the KAAU group and PDP group

\begin{tabular}{|c|c|c|c|c|c|c|}
\hline \multirow[t]{2}{*}{ Group/Grade } & \multicolumn{2}{|c|}{ KAAU } & \multicolumn{2}{|c|}{ PDP } & \multirow[t]{2}{*}{ Chi-Square } & \multirow[t]{2}{*}{ P-value } \\
\hline & $\%$ & $N$ & $\%$ & $N$ & & \\
\hline No/Slight need (Gr.I-4) & 72.7 & 355 & 37.41 & 95 & 150.222 & $0.000 *$ \\
\hline Moderate/Border line (Gr.5-7) & 14.3 & 70 & 40.55 & 103 & 6.295 & $0.000^{*}$ \\
\hline Need treatment (Gr.8-10) & 12.9 & 63 & 22.04 & 56 & 0.412 & 0.521 \\
\hline Total & & 488 & & 254 & & \\
\hline
\end{tabular}

* Significant at $\mathrm{p}<0.00 \mathrm{I}$ at I d.f.

lack of compliance seen among those patients. Little awareness for the actual need for treatment in the KAAU group could be attributed to the free treatment provided, which attracts anyone to seek treatment regardless of the severity of his or her malocclusion. Therefore, it is recommended to use the DHC of the IOTN as a screening tool to reevaluate the waiting lists of patients seeking orthodontic treatment at governmental clinics. This would identify those patients who could benefit the most from such free services and subsequently reduce the long waiting lists at such centers. In addition, the application of minimum charge for treatment at governmental dental clinics can serve the same purpose.

\section{Conclusion}

There is a definitive need for orthodontic treatment among Saudis living in the city of Jeddah, which is not matched with a similar level of perceptive need by the same population. The grades of AC and DHC were significantly different between those patients seeking free treatment at governmental dental centers and those who pay for their treatment at private dental practices.

\section{Competing interests}

The author(s) declare that they have no competing interests.

\section{Acknowledgements}

The author would like to thank Prof. Hala Amer, Dr. Amna Siddiqi and Dr. Reema Al Ghaithy at the Faculty of Dentistry, King Abdulaziz University for their valuable contributions.

\section{References}

I. Burden DJ, Pine CM: Self-perception of malocclusion among adolescents. Community Dent Health 1995, I 2:89-92.

2. Chew MT, Aw AK: Appropriateness of orthodontic referrals: self-perceived and normative treatment needs of patients referred for orthodontic consultation. Community Dent Oral Epidemiol 2002, 30:449-454.

3. Grzywacz I: The value of the aesthetic component of the Index of Orthodontic Treatment Need in the assessment of subjective orthodontic treatment need. Eur J of Orthod 2003, 25:57-63.

4. Gilbert GH, Heft MW, Duncan RP, Ringelberg ML: Perceived need for dental care in dentate older adults. Int Dent J 1994 , 44: $145-152$

5. Atchison KA, Matthias RE, Dolan TA, Lubben JE, De Jong F, Schweitzer SO, Mayer-Oakes SA: Comparison of oral health ratings by dentists and dentate elders. J Public Health Dent 1993, 53:223-230.

6. Matthias RE, Atchison KA, Lubben JE, De Jong F, Schweitzer SO: Factors affecting self-ratings of oral health. J Public Health Dent 1995, 55:197-204.

7. Heft MW, Gilbert GH, Shelton BJ, Duncan RP: Relationship of dental status, sociodemographic status, and oral symptoms to perceived need for dental care. Community Dent Oral Epidemiol 2003, 31:35I-360.

8. Lindsay SJ, Hodgkins JF: Children's perceptions of their own malocclusions. $\mathrm{Br}$ J Orthod 1983, 10:13-20.

9. Roberts EE, Beales JG, Dixon L, Willcocks AJ, Willmot DR: The orthodontic condition and treatment status of a sample of 14-year-old children in North Derbyshire. Community Dent Health 1989, 6:249-256.

10. Tulloch JF, Shaw WC, Underhill C, Smith A, Jones G, Jones M: A comparison of attitudes toward orthodontic treatment in British and American communities. Am J Orthod 1984, 85:253-259.

II. Brook PH, Shaw WC: The development of an index of orthodontic treatment priority. Eur J Orthod 1989, I I:309-320.

12. Burden DJ, Pine CM, Burnside G: Modified IOTN: an orthodontic treatment need index for use in oral health surveys. Community Dent Oral Epidemiol 200I, 29:220-225.

13. Hamdan AM: The relationship between patient, parent and clinician perceived need and normative orthodontic treatment need. Eur J Orthod 2004, 26:265-27I.

14. Richmond S, Shaw WC, O'Brien KD, Buchanan IB, Jones R, Stephens $C D$, Roberts CT, Andrews M: The development of the PAR Index (Peer Assessment Rating): reliability and validity. Eur J Orthod 1992, 14:125-139.

15. Daniels CP, Richmond S: The development of the Index of Complexity Outcome and Need (ICON). J Orthod 2000, 27:149-162.

16. Kuijpers MA, Kiekens RM: Research methods in dentistry 10. Assessment of orthodontic treatment need. Ned Tijdschr Tandheelkd 2005, I I 2:206-2 I 0.

17. Fox NA, Daniels C, Gilgrass T: A comparison of the index of complexity outcome and need (ICON) with the peer assessment rating (PAR) and the index of orthodontic treatment need (IOTN). Br Dent J 2002, 193:225-30.

18. Al Yami EA, Kuijpers-Jagtman AM, van't Hof MA: Orthodontic treatment need prior to treatment and 5 years postretention. Community Dent Oral Epidemiol 1998, 26:42।-427.

19. Birkeland K, Boe OE, Wisth PJ: Orthodontic concern among I Iyear-old children and their parents compared with orthodontic treatment need assessed by index of orthodontic treatment need. Am J Orthod Dentofacial Orthop 1996, I 1 0:197-205.

20. Tickle M, Kay EJ, Bearn D: Socio-economic status and orthodontic treatment need. Community Dental Oral Epidemiol 1999, 27:4|3-4|8.

21. Wang G, Hagg U, Ling J: The orthodontic treatment need and demand of Hong Kong Chinese children. Chin J Dent Res 1999, 2:84-92.

22. Mandall NA, Wright J, Conboy FM, O'Brien KD: The relationship between normative orthodontic treatment need and measures of consumer perception. Community Dent Health 200I, 18:3-6. 
23. Ahmed B, Gilthorpe MS, Bedi R: Agreement between normative and perceived orthodontic need amongst deprived multiethnic school children in London. Clin Orthod Res 200I, 4:65-7I.

24. Abdullah MS, Rock WP: Perception of dental appearance using Index of Treatment Need (Aesthetic Component) assessments. Community Dent Health 2002, 19:161-165.

25. Chew MT, Aw AK: Appropriateness of orthodontic referrals: self-perceived and normative treatment needs of patients referred for orthodontic consultation. Community Dent Oral Epidemiol 2002, 30:449-454.

26. Al-Sarheed M, Bedi R, Hunt NP: Orthodontic treatment need and self-perception of I I-16-year-old Saudi Arabian children with a sensory impairment attending special schools. J Orthod 2003, 30:39-44.

27. Helm S, Petersen PE, Kreiborg S, Solow B: Effect of separate malocclusion traits on concern for dental appearance. Community Dent Oral Epidemiol 1986, 14:217-220.

28. Espeland LV, Stenvik A: Perception of personal dental appearance in young adults: relationship between occlusion, awareness, and satisfaction. Am J Orthod Dentofacial Orthop 199I, 100:234-24I.

29. Abu Alhaija ES, Al-Nimri KS, Al-Khateeb SN: Self-perception of malocclusion among north Jordanian school children. Eur J Orthod 2005, 27:292-295.

30. Grzywacz I: The value of the aesthetic component of the Index of Orthodontic Treatment Need in the assessment of subjective orthodontic treatment need. Eur J Orthod 2003, 25:57-63.

31. Kerosuo H, Al Enezi S, Kerosuo E, Abdulkarim E: Association between normative and self-perceived orthodontic treatment need among Arab high school students. Am J Orthod Dentofacial Orthop 2004, 1 25:373-8.

32. Mugonzibwa EA, Kuijpers-Jagtman AM, Van't Hof MA, Kikwilu EN: Perceptions of dental attractiveness and orthodontic treatment need among Tanzanian children. Am J Orthod Dentofacial Orthop 2004, 1 25:426-33.

Publish with Bio Med Central and every scientist can read your work free of charge

"BioMed Central will be the most significant development for disseminating the results of biomedical research in our lifetime. "

Sir Paul Nurse, Cancer Research UK

Your research papers will be:

- available free of charge to the entire biomedical community

- peer reviewed and published immediately upon acceptance

- cited in PubMed and archived on PubMed Central

- yours - you keep the copyright

Submit your manuscript here:

http://www.biomedcentral.com/info/publishing_adv.asp
BioMedcentral 